\title{
Two-liquid-phase mesophilic and thermophilic biotrickling filters for the biodegradation of $\alpha$-pinene
}

\author{
María Montes, María C. Veiga, Christian Kennes \\ Bioresource Technologye, Volume 101, Issue 24, 2010, Pages 9493-9 \\ DOI: 10.1016/j.biortech.2010.07.101
}

\begin{abstract}
$\alpha$-Pinene biodegradation was evaluated in mesophilic and thermophilic biotrickling filters. The potential of silicone oil for enhancing the removal was evaluated too, at both temperatures. Performance was studied at empty bed residence times between 60 and $14 \mathrm{~s}$, and concentrations of $0.06-38.84 \mathrm{~g} \mathrm{~m}^{-3}$, with or without silicone oil. Efficiency decreased as the pollutant concentration was increased, showing higher elimination capacities at higher EBRTs. In the absence of silicone oil, better results were obtained in the thermophilic than in the mesophilic bioreactor. At similar loads ( $\left.360 \mathrm{~g} \mathrm{~m}^{-3} \mathrm{~h}^{-1}\right)$, in the thermophilic bioreactor the elimination capacity was $293 \mathrm{~g} \mathrm{~m}^{-3} \mathrm{~h}^{-1}$, with a removal efficiency of $81 \%$, while in the mesophilic BTF the elimination capacity only reached $195 \mathrm{~g} \mathrm{~m}^{-3} \mathrm{~h}^{-1}$, for that same load. The presence of a second liquid phase improved performance of both bioreactors. With 5\% silicone oil, elimination capacities as high as $2000 \mathrm{~g} \mathrm{~m}^{-3} \mathrm{~h}^{-1}$ were achieved, under either mesophilic or thermophilic conditions.
\end{abstract}

\section{Keywords}

$\alpha$-Pinene; Biodegradation; Steady-state; Shock load; Waste gases.

\section{Introduction}

The treatment of polluted air in bioreactors allows the complete destruction of contaminants, contrary to some conventional physico-chemical technologies. Biofiltration is a biological process that uses microorganisms to convert odor causing compounds into harmless end-products, i.e. carbon dioxide, water and biomass. Originally, most biofilters used naturally bioactive media such as peat, compost, soil or wood chips to biologically degrade odors and VOCs (Kennes and Veiga, 2002). Application of the biofiltration technology to the treatment of VOCs has been investigated by a large number of researchers (Kennes and Veiga, 2001 and Kennes et al., 2009a). In recent years, biotrickling filtration has received increasing attention for the treatment of compounds difficult to degrade or compounds that generate acidic products, such as $\mathrm{H}_{2} \mathrm{~S}$ (Jin et al., 2005). The principle of biotrickling filters is based on passing a contaminated air stream co- or counter-currently through a packed bed of inert materials on which a pollutant degrading biofilm is attached. At the same time, a continuous stream of a liquid phase trickles down through the packing material in order to keep the biofilm moist and biologically active. The trickling rate influences the pressure drop, the wetting of the packing and mass transfer of the pollutant to the biofilm. Performance of the biotrickling filter depends on several factors such as the 
mass transfer (diffusion, convection) and biological processes (growth, death and lysis, predation).

One key factor in biotrickling filter performance is temperature. Most biotrickling filter studies have been run at temperatures between 20 and $35^{\circ} \mathrm{C}$, typical of mesophilic microorganisms. However, many industrial streams are frequently released at different temperatures and most often higher than temperature ranges corresponding to the optimum activity of mesophilic microorganisms. The treatment of such hot gases has received only little attention (Van Lith et al., 1997). One alternative for their treatment would consist in cooling down hot waste gases, although this may be expensive. Another option would be the use of microorganisms adapted to high temperatures, avoiding the need to significantly cool down the effluent. For example, effective removal of $\alpha$-pinene and methanol at biotrickling filter temperatures of 60 and $70{ }^{\circ} \mathrm{C}$, respectively, has been demonstrated recently (Kong et al., 2001). The activity of any biocatalyst in a bioreactor, in terms of its growth and pollutant utilization rate, is usually expected to reach its maximum at specific temperatures, irrespective of its operation under mesophilic or thermophilic conditions. However, in industrial processes, the unexpected variations in flue gas temperature can easily alter the activity of the biocatalyst often composed of mixed populations, changing its optimal temperature for maximum activity, and subsequently the bioreactor performance. Recent literature has also shown that some mesophilic cultures can easily adapt to moderately thermophilic conditions $\left(55^{\circ} \mathrm{C}\right.$ ), irrespective of the nature of the pollutant treated (Gannoun et al., 2007). In the present research, $\alpha$-pinene, a monoterpene, was chosen as a representative VOC because of its environmental importance (Savithiry et al., 1998), its relevance in the application of biofiltration to emissions from the pulp and paper industry and the forest products industry (Dhamwichukorn et al., 2001) and because of our recent previous experience with this pollutant (Jin et al., 2006 and Jin et al., 2007). It is a hydrophobic compound with a relatively high boiling point $\left(155-156^{\circ} \mathrm{C}\right)$ and low water solubility (2.5 ppm at $23^{\circ} \mathrm{C}$ ) (Misra et al., 1996). Besides, $\alpha$-pinene has been identified as one of the most important VOCs, together with limonene, related to odor problems detected in compost plants.

Some recent studies have shown that the addition of an organic liquid phase, such as silicone oil, for the removal of poorly water soluble pollutants may significantly increase reactor performance (Aldric et al., 2010, Djeribi et al., 2005, Fazaelipoor and Shojaosadati, 2002, Kennes et al., 2009a and Rocha-Rios et al., 2010). In such systems, the hydrophobic organic phase acts as a reservoir, used to absorb poorly water-soluble organic pollutants from gaseous streams (Darracq et al., 2010, Daugulis, 2001 and Kennes et al., 2009b). Thus, microorganisms in the water phase will never be exposed to high, inhibitory pollutant concentrations accumulating in the organic reservoir (Bailón et al., 2009).

The main purpose of this work was to investigate the biodegradation of $\alpha$-pinene in biotrickling filters with lava rock as packing material, at thermophilic and mesophilic temperatures, firstly without the addition of silicone oil, and secondly, with the addition of 5\% (vol:vol) silicone oil. The performance of the one- and two-liquid-phase reactors were compared.

\section{Methods}




\subsection{Microbial seed and medium}

Both biotrickling filters (BTF) were inoculated with the leachate of a previously operated biofilter, containing predominantly Ophiostoma stenoceras, a fungus that has the ability to efficiently degrade $\alpha$-pinene under a wide range of operating conditions ( Jin et al., 2006). For the preparation of the inoculum, colonized packed bed was taken from another reactor. It was sonicated for $15 \mathrm{~min}$ and mixed with the above-mentioned leachate to obtain a mixed microbial consortium. Then it was cultured in $300 \mathrm{~mL}$ mineral medium in a $500 \mathrm{~mL}$ flask, for $7-8$ days under mesophilic conditions $\left(30^{\circ} \mathrm{C}\right)$, and for 1 month under thermophilic conditions $\left(45^{\circ} \mathrm{C}\right)$. The bottles were sealed with Teflon-lined screw caps, and $5 \mu \mathrm{L} \alpha$-pinene was added to the medium. The flasks were incubated in a rotary shaker and were continuously shaken at $170 \mathrm{rpm}$. After the cultures had degraded several successive additions of $\alpha$-pinene the medium was recirculated through the biotrickling filters using a peristaltic pump (model 323E/D Watson-Marlow Ltd., Falmouth, Cornwall, UK). The procedure was repeated several times until visible biomass was observed on the surface of the lava rock. The mineral salt medium used was as described previously ( Jin et al., 2007).

\subsection{Filter material}

The biotrickling filters were filled with irregular grains of lava rock as inert support. Lava rock was selected as packing material because of its large specific surface area, high porosity and relatively low price. Approximately 1\% by weight of plastic Pall rings was added at the bottom of the reactor to improve water drainage, as well as to reduce clogging. Some properties of the packing materials are summarized in Table 1.

Table 1.

Characteristics of the filter bed materials used in the experiment.

$\begin{array}{lllcl}\begin{array}{l}\text { Packing } \\ \text { material }\end{array} & \begin{array}{l}\text { Density } \\ \left(\mathbf{k g} / \mathbf{m}^{3}\right)\end{array} & \begin{array}{l}\text { Void } \\ \mathbf{( \% )}\end{array} & \begin{array}{r}\text { space Size } \\ \mathbf{( m m )}\end{array} & \begin{array}{l}\text { Specific } \\ \left(\mathbf{m}^{\mathbf{2}} \mathbf{g}^{-\mathbf{1}} \mathbf{)}\right.\end{array} \\ \text { Pall rings } & 80 & 91 & 15 & 350 \mathrm{~m}^{2} \mathrm{~m}^{-3} \\ \text { Lava rock } & 866.7 & 50 & 4-10 & 0.55\end{array}$

\subsection{Biotrickling filters}

The schematic of the biotrickling filters used in this study is as published previously (Bailón et al., 2009). Each bioreactor was operated at a different temperature: one at ambient temperature (approximately $23^{\circ} \mathrm{C}$ ) and the other one under thermophilic conditions (approximately $50^{\circ} \mathrm{C}$ ). The biotrickling filters consisted on a cylindrical glass column with an internal diameter (ID) of $10 \mathrm{~cm}$ and $70 \mathrm{~cm}$ in height, while the filter bed volume was $4 \mathrm{~L}$. All fittings, connections and tubings were made of Teflon. As already mentioned, lava rock was used as packing material. A perforated plate at the bottom of the reactor provided the support for the packing material. It was covered by a Pall ring layer to improve water drainage as well as to prevent clogging. Another plate at the top acted as a distributor for the gas flow and mineral medium distribution. 
Four equidistant gas sampling ports sealed with rubber septa were available at equal intervals of $20 \mathrm{~cm}$ along the biofilter height $(H)$. The waste gas stream and the liquid phase passed co-currently through the packed bed, in a down-flow mode. Basically, the experimental set-up was similar as described previously ( Bailón et al., 2009). A water jacket allowed maintaining a constant temperature in the thermophilic bioreactor by using a heating/re-circulating pump with a temperature set point of $56^{\circ} \mathrm{C}$ (Polyscience model 8012). In this way, the temperature inside the reactor reached $50{ }^{\circ} \mathrm{C}$. Mineral liquid medium was introduced into both systems using a Watson-Marlow peristaltic pump. The trickling solution was recycled to supply nutrients for microbial growth and to supply water to compensate for water evaporation. The liquid in the holding tank was mixed by means of a magnetic stirrer. The total liquid volume amounted to $1.5 \mathrm{~L}$. The aqueous mineral medium was renewed every 4 days in order to improve the pollutant elimination and the general dynamics of the biotrickling filter. The polluted gas stream was generated by mixing two different air streams. A large stream of compressed air was humidified by passing it through a bottle with water which was submerged in a temperature-controlled water bath maintained at $37^{\circ} \mathrm{C}$. A small stream of air was bubbled through a vial containing pure $\alpha$-pinene and was mixed with the larger humidified gas stream. The flow rates of both gas streams were measured and regulated with flow meters (Brooks Sho-Rate II). The operating parameters are summarized in Table 2.

Table 2.

Reactor characteristics and standard operating conditions.

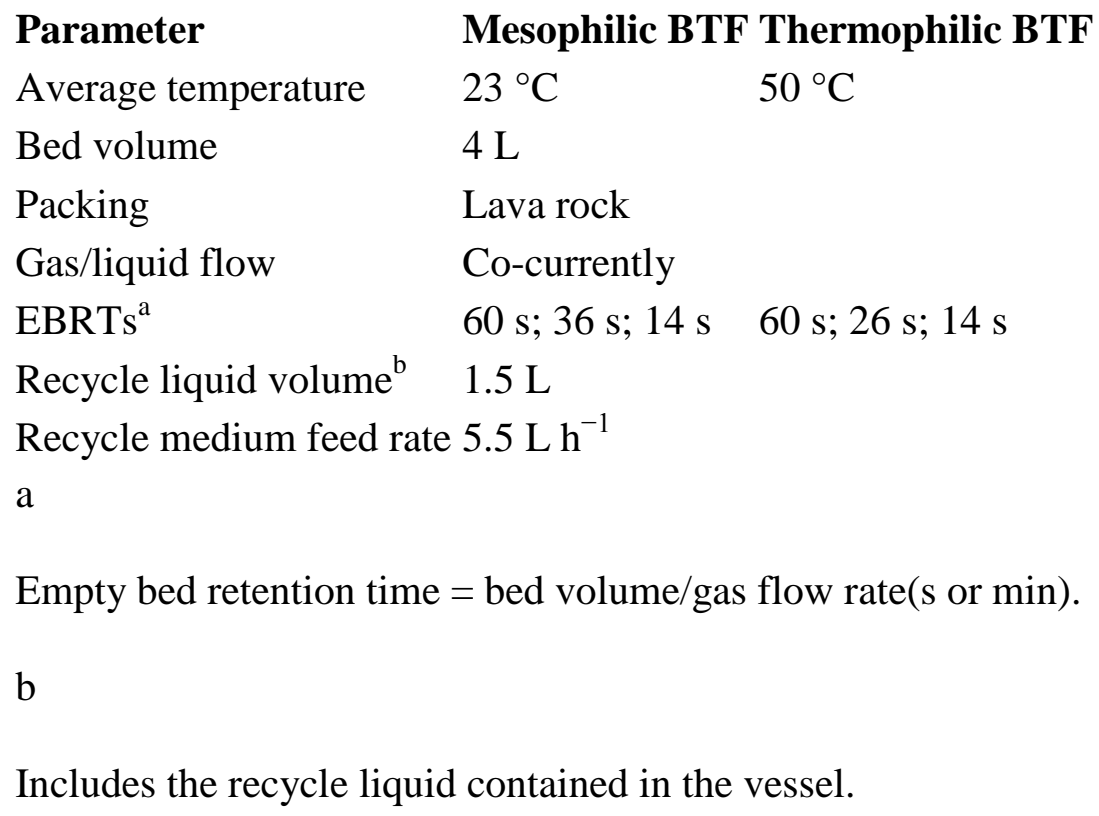

Bioreactor performance and removal efficiency of the systems in the treatment of $\alpha$ pinene, with and without silicone oil, were evaluated over more than 1 year. During the start-up of the biotrickling filters, mild conditions were used for acclimation of the biomass.

Experiments were carried out by varying the flow rates of the $\alpha$-pinene vapors and humidified air independently to get different initial concentrations and residence times 
in the biotrickling filters. Gas samples were collected from different ports and analyzed for $\alpha$-pinene and carbon dioxide concentrations.

\subsection{Batch biodegradation experiments}

Batch experiments were performed at least in duplicate at two different concentrations. Autoclaved medium was used. The experiments were done with biomass as used to inoculate the mesophilic and thermophilic reactors operated without silicone oil. The mineral medium described above $(9 \mathrm{~mL})$, with vitamins and trace minerals, was introduced into $100 \mathrm{~mL}$ bottles closed with rubber stoppers and aluminium caps. The pollutant was added, to reach a gas-phase concentration of about $40 \mathrm{~g} \mathrm{~m}^{-3}$. The bottles were maintained in a thermostatic shaker at 30 or $45^{\circ} \mathrm{C}$ with constant shaking at $170 \mathrm{rpm}$. The decrease of pollutant concentration and the production of $\mathrm{CO}_{2}$ were followed at different time intervals by injecting headspace samples into the gas chromatograph.

\subsection{Analytical methods}

Gas-phase concentrations of $\alpha$-pinene in the biotrickling filters and in batch assays were measured using a Hewlett-Packard 6890 gas chromatograph and a $50 \mathrm{~m}$ TRACER column (TR-WAX, internal diameter $0.32 \mathrm{~mm}$, film thickness $1.2 \mu \mathrm{m}$ ), equipped with a flame ionization detector. The flow rates were $30 \mathrm{~mL} \mathrm{~min}^{-1}$ for $\mathrm{H}_{2}$ and $300 \mathrm{~mL} \mathrm{~min}^{-1}$ for air. Helium was used as the carrier gas at a flow rate of $2 \mathrm{~mL} \mathrm{~min}^{-1}$. The temperatures at the GC injection, oven and detection ports were 250, 120 and $250{ }^{\circ} \mathrm{C}$, respectively. The inlet and outlet streams were sampled, as well as the air between the different biofilter sections. Inlet and outlet gas samples were taken by means of a Terumo gas-tight $2.5 \mathrm{~mL}$ syringe. Similarly, the $\mathrm{CO}_{2}$ concentration was analyzed with a HP 5890 gas chromatograph equipped with a thermal conductivity detector (TCD) and a Porapack Q-column W80/100. The injection and oven temperatures were 90 and $25^{\circ} \mathrm{C}$, respectively, with the TCD set at $100^{\circ} \mathrm{C}$. To quantify the clogging rate, pressure drop was measured using a U-tube manometer filled with water at the inlet and at the outlet of the BTF. A minimum division length reading of $1 \mathrm{~mm}$ water column was used. The pressure drop was calculated from the difference between the inlet and outlet valves of the manometer. The temperature of the filter bed was measured by means of a Digital Multi-thermometer $\left(-50\right.$ to $\left.+150^{\circ} \mathrm{C}\right)$.

\section{Results and discussion}

\subsection{Batch biodegradation experiments}

Batch biodegradation experiments were conducted to determine the potential of mesophilic and thermophilic degradation of $\alpha$-pinene using the same inoculum as for the continuous reactors, containing predominantly, but not exclusively, the fungal Ophiostoma species. The results of the batch biodegradation tests at 30 and $45^{\circ} \mathrm{C}$ are shown in Fig. 1. In all cases, the degradation rates were higher in the mesophilic than in the thermophilic batch assays. Most of the degraded substrate was recovered as carbon dioxide, identified by GC as end-product (data not shown), the rest of the substrate being converted into biomass. Thus, the batch experiments proved that $\alpha$-pinene could be degraded both at room temperature as well as at thermophilic temperatures. Removal 
was faster under mesophilic conditions because the original inoculum was a mesophilic culture, and no temperature adaptation was required under such condition.

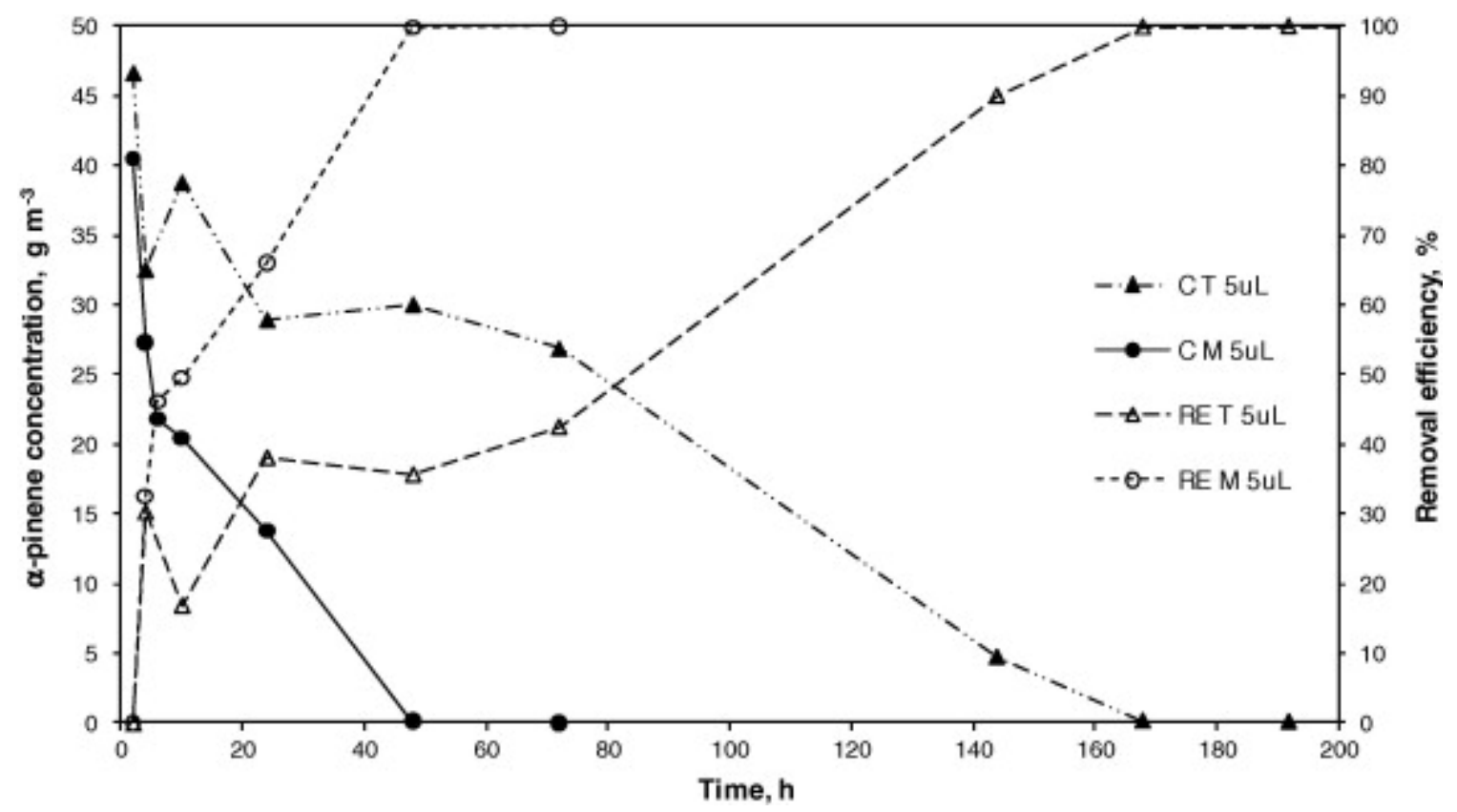

Fig. 1.

Batch $\alpha$-pinene degradation by mesophilic and thermophilic microorganisms (C T, concentration profile under thermophilic conditions; C M, concentration profile under mesophilic conditions; RE, removal efficiency).

\subsection{Biotrickling filters performance without silicone oil}

\subsubsection{Reactors performance}

The performance of the BTFs was evaluated in terms of the removal efficiency (RE, \%) and the elimination capacity (EC, $\mathrm{g} \mathrm{m}^{-3} \mathrm{~h}^{-1}$ ) at different inlet loading rates (ILR) as defined elsewhere (Kennes and Veiga, 2001 and Kennes et al., 2009a). During the first days of operation, low $\alpha$-pinene loads were used. Although similar loads were used in both reactors, the acclimation period was much higher in case of the thermophilic BTF, around 1 month, and shorter in the case of mesophilic system, around 10 days. This can be explained by the fact that, as in batch assays, the original inoculum was a mesophilic culture and it needed to get adapted to high temperatures. It is worth to observe that although a mesophilic inoculum was used, thermophilic microorganisms ended-up growing rather easily on the packing material. Similar results were obtained previously by other researchers in which the time for acclimation increased with increasing temperature, with shorter start-up periods at room temperature than under thermophilic conditions (Kong et al., 2001 and Luvsanjamba et al., 2007).

Following the successful start-up, the performance of the BTFs was investigated at three different empty bed residence times (EBRT), parameter which is known to significantly affect the efficiency of bioreactors. For the thermophilic system, inlet flow rates of 250, 550 and $1000 \mathrm{~L} \mathrm{~h}^{-1}$, corresponding to EBRTs of 60, 26 and $14 \mathrm{~s}$, respectively, were studied. For the mesophilic BTF, inlet flow rates of 250,400 and $1000 \mathrm{~L} \mathrm{~h}^{-1}$, corresponding to EBRTs of 60, 36 and 14 s, respectively, were used. The inlet $\alpha$-pinene 
concentration was gradually increased for each EBRT in order to evaluate the reactors performance. In all cases, the relationship between load and EC was linear up to a critical value, after which the EC approached a maximum value asymptotically (Fig. 2a). Though fluctuations were found in the EC values, a linear relationship between EC and ILR was observed in both BTF. In the thermophilic system, maximum ECs of 332, 299 and $263 \mathrm{~g} \mathrm{~m}^{-3} \mathrm{~h}^{-1}$ were observed at EBRTs of 60, 26 and $14 \mathrm{~s}$, respectively. From Fig. 2a it can be seen that a near complete elimination capacity could be maintained up to a load of about $235 \mathrm{~g} \mathrm{~m}^{-3} \mathrm{~h}^{-1}$ at an EBRT of $60 \mathrm{~s}$, while it dropped to $122 \mathrm{~g} \mathrm{~m}^{-3} \mathrm{~h}^{-1}$ at the lowest EBRT of $14 \mathrm{~s}$. In the mesophilic BTF maximum ECs of 232, 130 and $60 \mathrm{~g} \mathrm{~m}^{-3} \mathrm{~h}^{-1}$ were observed at EBRT of 60,36 and $14 \mathrm{~s}$, respectively (Fig. 2b). A near complete EC could be maintained up to a load of about $115 \mathrm{~g} \mathrm{~m}^{-3} \mathrm{~h}^{-1}$ at an EBRT of $60 \mathrm{~s}$, while it dropped to about $30 \mathrm{~g} \mathrm{~m}^{-3} \mathrm{~h}^{-1}$ at an EBRT of $14 \mathrm{~s}$.
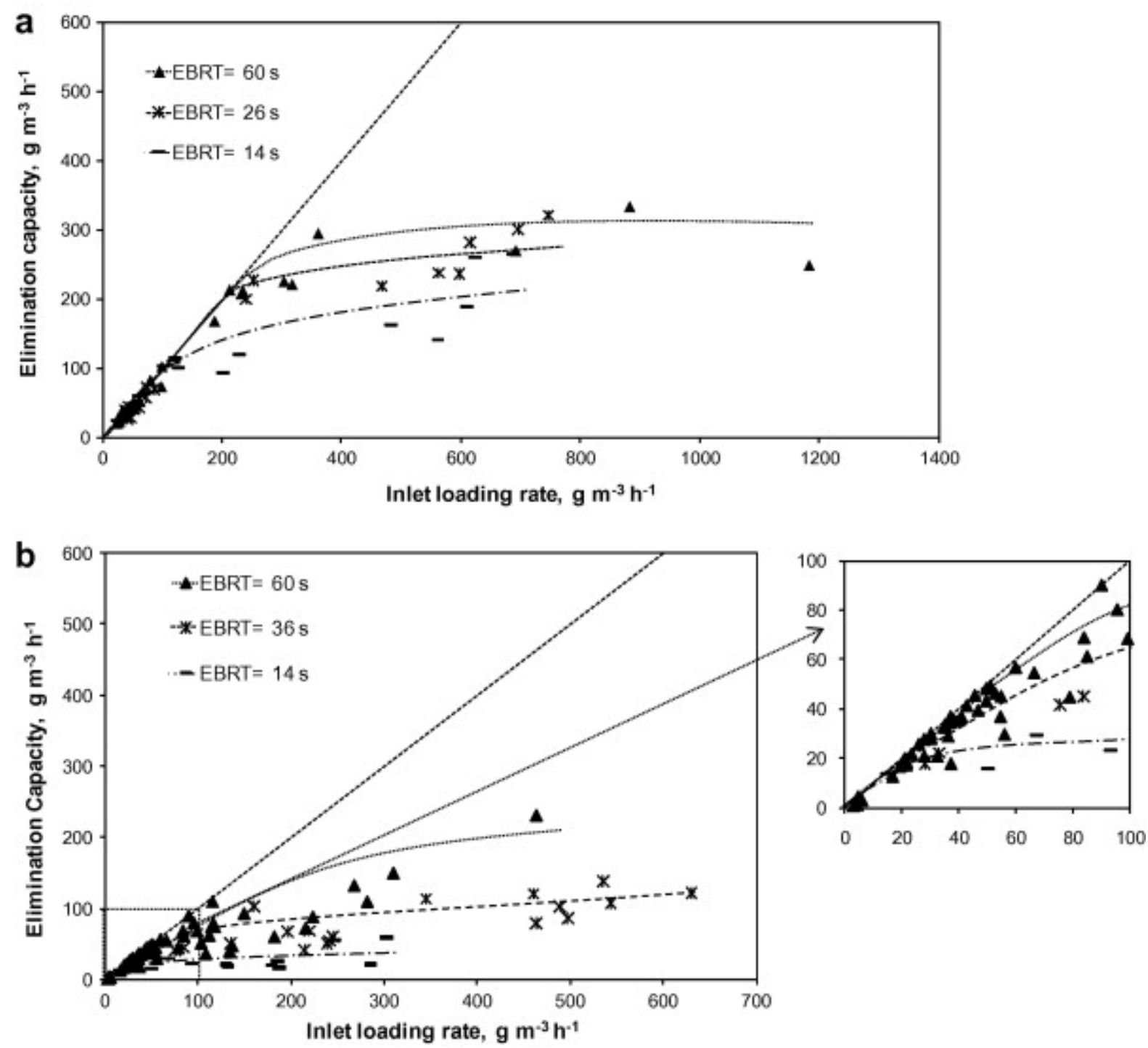

Fig. 2.

Effect of inlet loading rate on the elimination capacity of (a) the thermophilic BTF and (b) the mesophilic BTF. The straight line represents $100 \%$ removal efficiency. 
Thus, it can be concluded that in both BTFs the maximum EC and ILR clearly dropped when reducing the EBRT. It is also clear that a better performance was reached under thermophilic conditions, which was also observed recently by others (Luvsanjamba et al., 2007 and Mohammad et al., 2007).

\subsubsection{Removal profiles at different BTF depths}

The concentration at different heights in the filter bed was measured for both BTFs at different operating loads. Four sampling ports were located across the bed height. The ratio between the outlet $\alpha$-pinene concentration and the inlet concentration is presented in Fig. 3. The results show that a rather linear removal profile is observed over the first, second and third sections of the filter bed, both in the mesophilic and the thermophilic reactor. The removal is less or even negligible close to the outlet of the reactors, which can be attributed to an uneven biomass growth on the packing material. Such nonhomogenous biomass distribution and biodegradation profile is not unusual in packedbed gas-phase bioreactors (Kennes and Veiga, 2002). Very similar results were found at other EBRTs and inlet concentrations (data not shown).

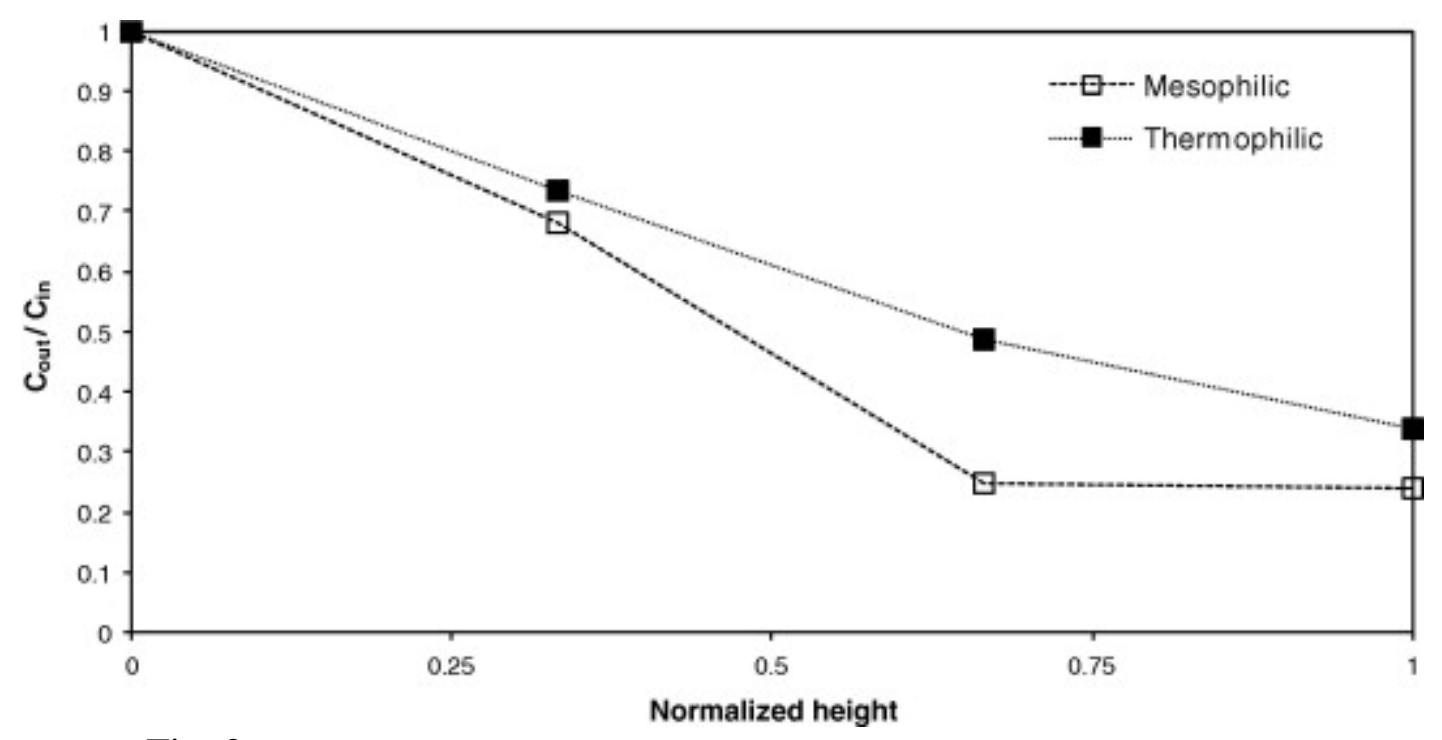

Fig. 3.

$\alpha$-Pinene removal profile for an inlet concentration of $0.2 \mathrm{~g} \mathrm{~m}^{-3}$ and an $\mathrm{EBRT}=22 \mathrm{~s}(\mathbf{\square})$ for the thermophilic BTF, and for an inlet concentration of $0.3 \mathrm{~g} \mathrm{~m}^{-3}$ and an EBRT $=36 \mathrm{~s} \mathrm{( \square )}$ for the mesophilic BTF.

\subsubsection{Shock loads}

The behaviour of both the thermophilic and the mesophilic BTF was investigated when subjecting them to shock load conditions. In both cases the shock load was performed at an EBRT of $36 \mathrm{~s}$. The pollutant load was varied from 25 to $600 \mathrm{~g} \mathrm{~m}^{-3} \mathrm{~h}^{-1}$, approximately. The results are shown in Fig. 4a for the thermophilic reactor. The removal efficiency at low inlet concentrations of $\alpha$-pinene, before the shock loads, was around $90 \%$. When the $\alpha$-pinene concentration was increased, immediate inhibition was observed. The removal efficiency dropped suddenly to $15 \%$ and then increased somewhat during the shock load. The response of the biotrickling filter was fast as seen in the removal profile at high loads as well as the quick retrieval in performance (RE 
$>90 \%$ ), when restoring low loads. The biotrickling filter recovered almost instantaneously, showing the robustness of such reactor.
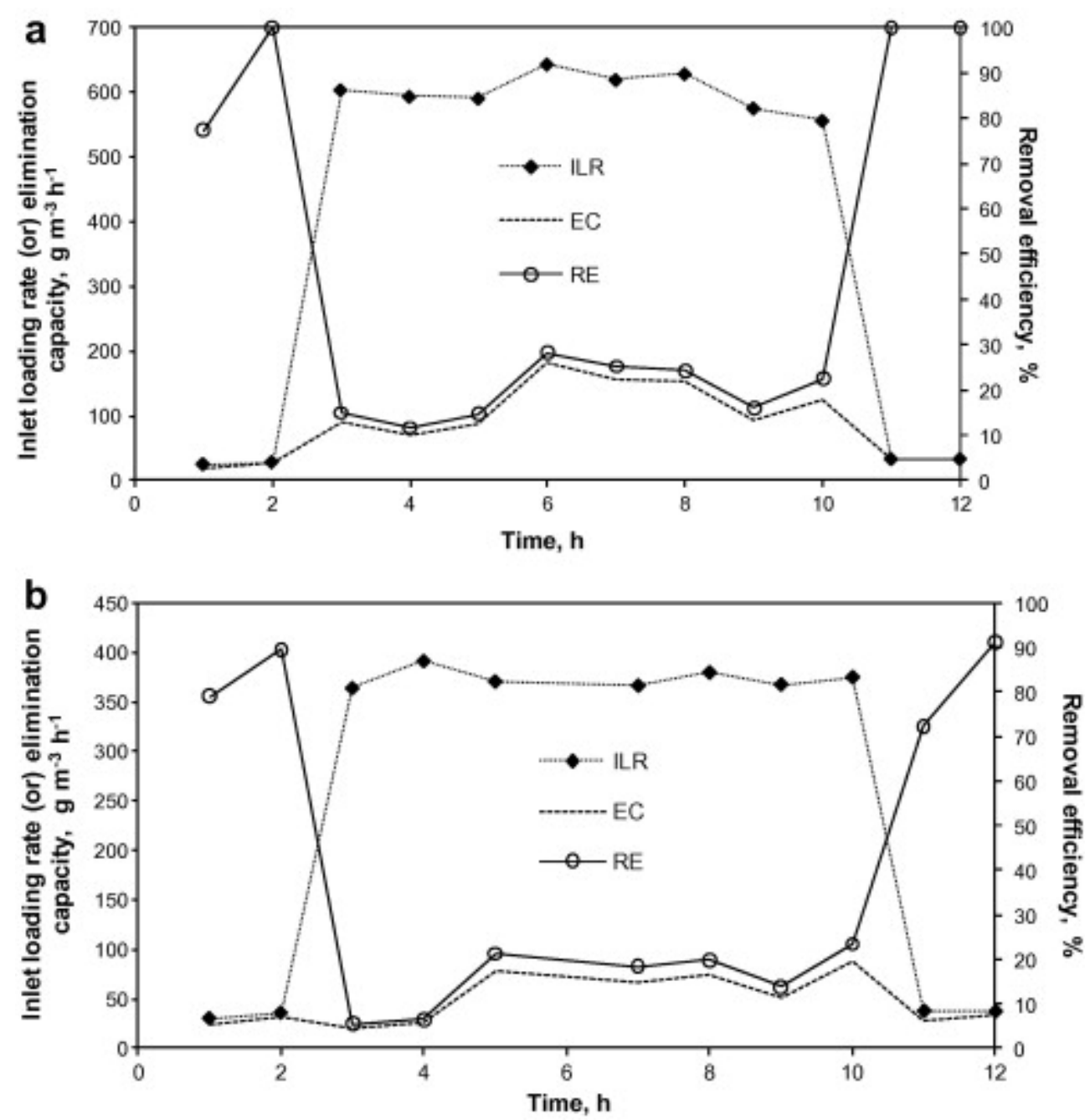

Fig. 4.

Effect of shock loads on the removal efficiency of (a) the thermophilic BTF and (b) the mesophilic BTF, at an EBRT = $36 \mathrm{~s}$.

In the case of the mesophilic BTF, the shock load was applied at an EBRT of $36 \mathrm{~s}$ and loads between 30 and $400 \mathrm{~g} \mathrm{~m}^{-3} \mathrm{~h}^{-1}$ were used. The results show that as soon as the shock load was applied, the removal efficiency dropped suddenly by $90 \%$ (Fig. 4b). As in the case of the thermophilic bioreactor, after the shock load was started, the removal efficiency increased somewhat, to $20 \%$ after $2 \mathrm{~h}$, to remain roughly constant afterwards. When low loads were re-established, the original removal profile was recovered. Comparing both systems it can be seen that the performance of the bioreactor under overload conditions is better in the thermophilic than in the mesophilic system, because although a lower shock load was applied in the mesophilic reactor, the removal efficiency and the elimination capacity were still 56\% higher in the thermophilic BTF.

These results clearly show the sensitivity of the BTFs to changes in loading rate due to variations in concentration and flow rate. Despite some differences, both the mesophilic 
and thermophilic reactors recovered quite fast after the overloads and showed a similar behaviour, although stability was somewhat higher at higher temperature.

\subsection{Biotrickling filters performance in presence of silicone oil}

\subsubsection{Silicone oil retention}

Several experiments were carried out in order to check to what extent silicone oil was adsorbed on the lava rock. The experimental set-up used for this study consisted of a $70 \mathrm{~cm}$ high glass biotrickling filter, with an internal diameter of $10 \mathrm{~cm}$, filled with $500 \mathrm{~mL}$ lava rock. Different volumes of silicone oil were added. The volume retained in the reactor was measured $10 \mathrm{~min}$ after the addition. The amount silicone oil adsorbed is shown in Table 3 , for both the mesophilic $\left(23^{\circ} \mathrm{C}\right)$ and thermophilic $\left(50{ }^{\circ} \mathrm{C}\right)$ systems. From Table 3, it can be seen that $66 \mathrm{~mL}$ silicone oil was retained per liter lava rock in the mesophilic reactor, while this value dropped down to $39 \mathrm{~mL}$ silicone oil/L lava rock under thermophilic conditions. Oil retention after a second addition was also checked, showing that some additional amount of silicone oil was adsorbed but in a lower amount. Here also, more oil was retained in the mesophilic system than in the thermophilic one.

Table 3.

Results of silicone oil adsorption.

\begin{tabular}{lll} 
& \multicolumn{2}{c}{ Silicone oil adsorbed $(\mathbf{m L} / \mathbf{L})$} \\
\cline { 2 - 3 } & Mesophilic & Thermophilic \\
1st addition oil & 66 & 39 \\
2nd addition oil 30 & 22
\end{tabular}

The results from the adsorption test showed that lava rock had a relatively high adsorption capacity for silicone oil and that, for each oil addition, about 50\% more volume was retained in the mesophilic than in the thermophilic reactor.

\subsubsection{Biotrickling filters performance with silicone oil}

In the next experimental stage, new studies were carried out using the same BTF and conditions as without silicone oil, but $5 \%$ (vol:vol) silicone oil was added as organic phase to the trickling liquid re-circulated through the BTF. The BTFs were operated for 200 days under these conditions. During the first days, low $\alpha$-pinene loads were fed. The inlet pollutant concentration was later gradually increased while maintaining the air flow rate constant, in order to evaluate both reactors' performance. For 20 days the BTFs were operated at an empty bed residence time of $60 \mathrm{~s}$, varying the load between 20 and $1700 \mathrm{~g} \mathrm{~m}^{-3} \mathrm{~h}^{-1}$. In both BTFs only 4 days were necessary to achieve removal efficiencies of $100 \%$. Afterwards, the EBRT was decreased down to 48 and $36 \mathrm{~s}$ in the mesophilic and thermophilic systems, respectively (Fig. 5). In this phase, the bioreactors were operated for about 95 days. As shown in Fig. 5a, in the mesophilic system the maximum loading rate tested at this EBRT was about $3300 \mathrm{~g} \mathrm{~m}^{-3} \mathrm{~h}^{-1}$. The removal efficiency could be maintained at $98.4 \%$, which corresponds to an $\alpha$-pinene elimination 
capacity of $3249 \mathrm{~g} \mathrm{~m}^{-3} \mathrm{~h}^{-1}$. No higher values were used since the present ones were already very high for gas-phase bioreactors. In the thermophilic BTF the maximum loading rate reached at an EBRT of $36 \mathrm{~s}$ was about $2232 \mathrm{~g} \mathrm{~m}^{-3} \mathrm{~h}^{-1}$, with a removal efficiency of 78.9\%, and a pollutant elimination capacity of $1762 \mathrm{~g} \mathrm{~m}^{-3} \mathrm{~h}^{-1}$ (Fig. 5b).
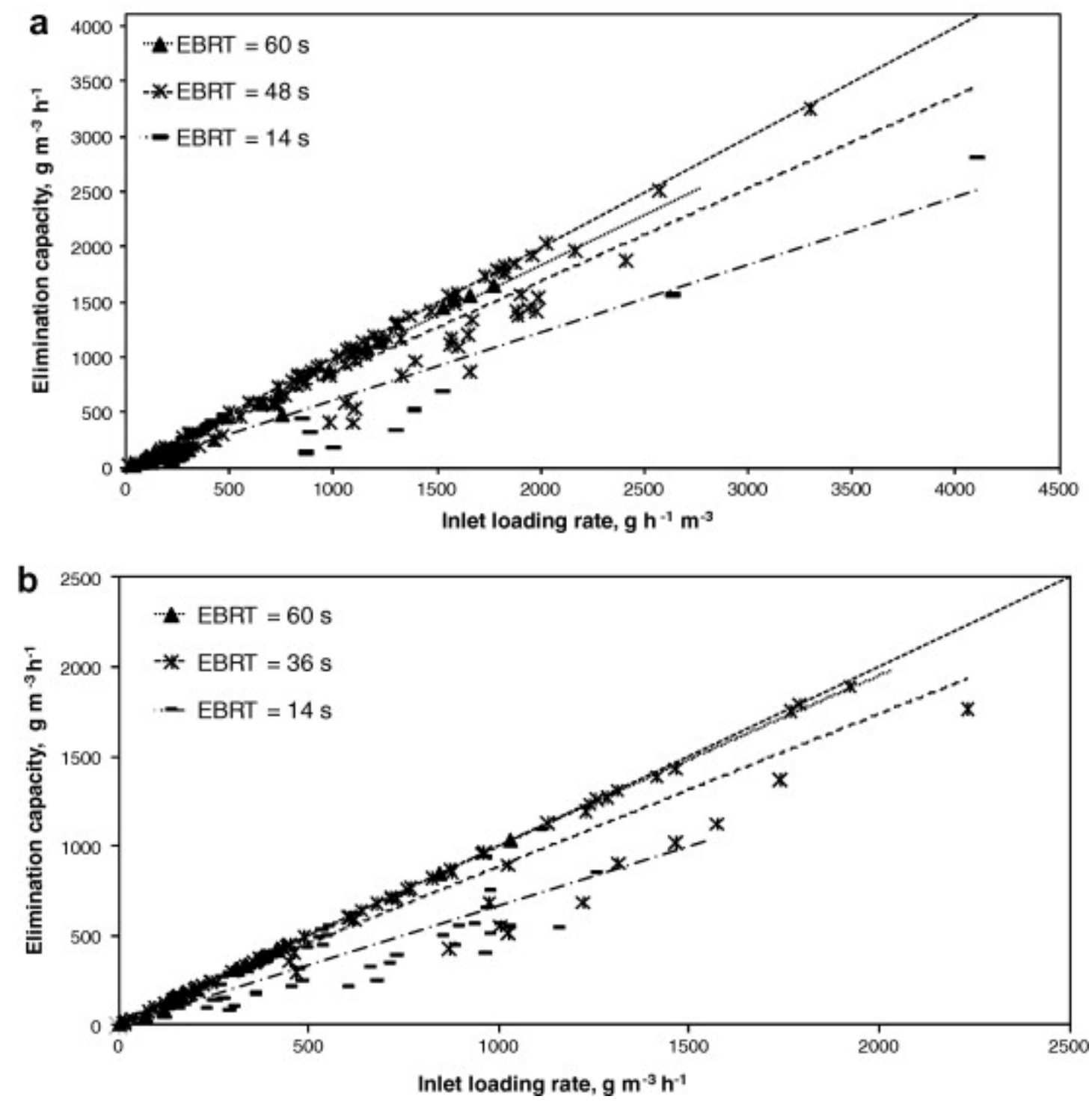

Fig. 5.

Elimination capacity vs. inlet loading rate in the presence of silicone oil for (a) the mesophilic BTF and (b) the thermophilic BTF.

Next, BTF performance was investigated at a lower EBRT of $14 \mathrm{~s}$. The flow rate and concentrations were adjusted to yield loading rates ranging from $110 \mathrm{~g} \mathrm{~m}^{-3} \mathrm{~h}^{-1}$ to as high as about $4000 \mathrm{~g} \mathrm{~m}^{-3} \mathrm{~h}^{-1}$. Though there were fluctuations in the EC values during the start-up, it can be observed that in the mesophilic system the maximum loading rate reached was $4107 \mathrm{~g} \mathrm{~m}^{-3} \mathrm{~h}^{-1}$ with an elimination capacity of $2810 \mathrm{~g} \mathrm{~m}^{-3} \mathrm{~h}^{-1}$ that corresponds to a removal efficiency of $68 \%$. In the thermophilic system the maximum elimination capacity reached was $853 \mathrm{~g} \mathrm{~m}^{-3} \mathrm{~h}^{-1}$ for a loading rate of $1257 \mathrm{~g} \mathrm{~m}^{-3} \mathrm{~h}^{-1}$, which corresponds to $68 \%$ removal efficiency, the same value as reached in the mesophilic system but at higher loading rates. 
The performance of the mesophilic and thermophilic biotrickling filters with and without the addition of silicone oil is summarized in Table 4. Overall, performance was clearly better in the thermophilic bioreactor than in the mesophilic one without oil. Such difference was, however, not observed when adding 5\% silicone oil. Performance of the mesophilic reactor was even slightly better than for the thermophilic one, which could be related to the worse oil retention at higher temperature.

Table 4.

Maximum $\alpha$-pinene elimination capacities expressed in terms of the reactors volume for the mesophilic and thermophilic biotrickling filters, with and without the addition of silicone oil.

$\begin{array}{lcc}\begin{array}{l}\text { Experiment } \\ \text { Mesophilic BTF }\end{array} & \mathbf{E} \mathbf{C}_{\mathbf{m a x}}\left(\mathbf{g ~ m}^{\mathbf{- 3}} \mathbf{h}^{\mathbf{- 1}}\right) \mathbf{I L R}\left(\mathbf{g ~ m}^{\mathbf{- 3}} \mathbf{h}^{\mathbf{- 1}}\right) \mathbf{R E} \mathbf{\%} \\ \begin{array}{l}\text { One liquid phase } 232 \\ \text { Two liquid phase } 3249\end{array} & 464 & 50 \\ \text { Thermophilic BTF } & 3302 & 98 \\ \text { One liquid phase } 332 & & \\ \text { Two liquid phase } 1889 & 882 & 38 \\ & 1922 & 98\end{array}$

Pressure drop was measured during the experiments in both the thermophilic and the mesophilic BTFs in presence of silicone oil. A similar behaviour was observed in both cases, with the pressure drop remaining basically constant and around $5 \mathrm{~cm} \mathrm{H}_{2} \mathrm{O}$ at a flow rate of $0.4 \mathrm{~m}^{3} \mathrm{~h}^{-1}$, i.e. EBRT of $36 \mathrm{~s}$. Nevertheless, when the flow rate was increased up to $1.0 \mathrm{~m}^{3} \mathrm{~h}^{-1}$ (EBRT of $14 \mathrm{~s}$ ), the pressure drop increased in both systems,

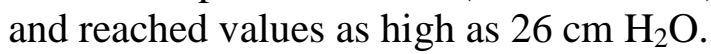

To avoid excess biomass accumulation and/or when the reactor performance dropped significantly, different strategies were applied, including manual mixing of the packing material or backwashing (Kennes and Veiga, 2002 and Mendoza et al., 2004).

\section{Conclusions}

The thermophilic BTF without silicone oil was more efficient than the mesophilic one for the treatment of $\alpha$-pinene polluted air, achieving near complete pollutant degradation up to a load of $235 \mathrm{~g} \mathrm{~m}^{-3} \mathrm{~h}^{-1}$ at an EBRT of $60 \mathrm{~s}$. In the mesophilic BTF, complete pollutant degradation was reached up to a load of $115 \mathrm{~g} \mathrm{~m}^{-3} \mathrm{~h}^{-1}$ at the same EBRT. The thermophilic bioreactor showed a higher EC and higher pressure drop than the mesophilic one. Higher degradations were obtained using a biphasic liquid mixture composed of silicone oil and an aqueous medium (5:95, vol:vol). Also, better results were obtained under mesophilic than thermophilic conditions, with oil. 


\section{Acknowledgements}

The present research and the Ph.D. contract of M. Montes were financed through a project of the Spanish Ministry of Science and Innovation (CTM2007-62700/TECNO) and through European FEDER funds. We thank M.E. López and E.R. Rene for their collaboration in some of the experimental studies.

\section{References}

J.-M. Aldric, S. Gillet, F. Delvigne, P. Thonart

Development of an original approach to evaluate effects of surfactants, biomass and pollutants on the scaling-up of a two-phase partitioning bioreactor

J. Chem. Technol. Biotechnol., 85 (2010), pp. 356-363

L. Bailón, M. Nikolausz, M. Kästner, M.C. Veiga, C. Kennes

Removal of dichloromethane from waste gases in one- and two-liquid-phase stirred tank bioreactors and biotrickling filters

Water Res., 43 (2009), pp. 11-20

G. Darracq, A. Couvert, C. Couriol, A. Amrane, D. Thomas, E. Dumont, Y. Andrès, P. Le Cloirec

Silicone oil: an effective absorbent for the removal of hydrophobic volatile organic compounds

J. Chem. Technol. Biotechnol., 85 (2010), pp. 309-313

A.J. Daugulis

Two-phase partitioning bioreactors: a new technology platform for destroying xenobiotics

Trends Biotechnol., 19 (2001), pp. 457-462

S. Dhamwichukorn, G.T. Kleinheinz, S.T. Bagley

Thermophilic biofiltration of methanol and $\alpha$-pinene

J. Ind. Microbiol. Biotechnol., 26 (2001), pp. 127-133

R. Djeribi, T. Dezenclos, A. Pauss, J.-M. Lebeault

Removal of styrene from waste gas using a biological trickling filter

Eng. Life Sci., 5 (2005), pp. 450-457

M.H. Fazaelipoor, S.A. Shojaosadati

The effect of silicone oil on biofiltration of hydrophobic compounds

Environ. Prog., 21 (2002), pp. 221-224

Gannoun et al., 2007

H. Gannoun, N.B. Othman, H. Bouallagui, H. Moktar

Mesophilic and thermophilic anaerobic co-digestion of olive mill wastewaters and abattoir wastewaters in an up-flow anaerobic filter

Ind. Eng. Chem. Res., 46 (2007), pp. 6737-6743 
Y. Jin, M.C. Veiga, C. Kennes

Effects of $\mathrm{pH}, \mathrm{CO}_{2}$ and flow pattern on the autotrophic degradation of hydrogen sulphide in a biotrickling filter

Biotechnol. Bioeng., 92 (2005), pp. 462-471

Y. Jin, M.C. Veiga, C. Kennes

Performance optimization of the fungal biodegradation of $\alpha$-pinene in gas-phase biofilter

Proc. Biochem., 41 (2006), pp. 1722-1728

Y. Jin, L. Guo, M.C. Veiga, C. Kennes

Fungal biofiltration of $\alpha$-pinene: effects of temperature, relative humidity and transient loads

Biotechnol. Bioeng., 96 (2007), pp. 433-443

C. Kennes, M.C. Veiga

Bioreactors for Waste Gas Treatment

Kluwer Academic Publishers, Dordrecht, The Netherlands (2001)

C. Kennes, M.C. Veiga

Inert filter media for biofiltration of waste gases-characteristics and biomass control

Rev. Environ. Sci. Biotechnol., 1 (2002), pp. 201-214

C. Kennes, E.R. Rene, M.C. Veiga

Bioprocesses for air pollution control

J. Chem. Technol. Biotechnol., 84 (2009), pp. 1419-1436

C. Kennes, M. Montes, M.E. López, M.C. Veiga

Waste gas treatment in bioreactors: environmental engineering aspects

Can. J. Civil Eng., 36 (2009), pp. 1887-1894

Z. Kong, L. Farhana, R.R. Fulthorpe, D.G. Allen

Treatment of volatile organic compound in a biotrickling filter under thermophilic conditions

Environ. Sci. Technol., 35 (2001), pp. 4347-4352

M. Luvsanjamba, B. Sercu, S. Kertész, H. Van Langenhove

Thermophilic biotrickling filtration of a mixture of isobutyraldehyde and 2-pentanone

J. Chem. Technol. Biotechnol., 82 (2007), pp. 74-80

G. Misra, S.G. Pavlostathis, E.M. Perdue, R. Araujo

Aerobic biodegradation of selected monoterpenes

Appl. Microbiol. Biotechnol., 45 (1996), pp. 831-838

J.A. Mendoza, O.J. Prado, M.C. Veiga, C. Kennes

Hydrodynamic behaviour and comparison of technologies for the removal of excess biomass in gas-phase biofilters

Water Res., 38 (2004), pp. 404-413 
B.T. Mohammad, M.C. Veiga, C. Kennes

Mesophilic and thermophilic biotreatment of BTEX-polluted air in reactors

Biotechnol. Bioeng., 97 (2007), pp. 1423-1438

J. Rocha-Rios, R. Muñoz, S. Revah

Effect of silicone oil fraction and stirring rate on methane degradation in a stirred tank bioreactor

J. Chem. Technol. Biotechnol., 85 (2010), pp. 314-319

N. Savithiry, D. Gage, W. Fu, P. Oriel

Degradation of pinene by Bacillus pallidus BR425

Biodegradation, 9 (1998), pp. 337-341

C. Van Lith, G. Leson, R. Michelson

Evaluating design option for biofilters

J. Air Waste Manage. Assoc., 47 (1997), pp. 37-48 